\title{
POESÍAS INÉDITAS DEL PRÍNCIPE DE ESQUILACHE
}

Gracias a nuestro erudito amigo don Antonio Rodríguez-Moñino nos ha sido posible manejar un códice que contiene poesías del Príncipe de Esquilache, de encuadernación moderna, con toda seguridad del siglo xix. El tejuelo del pergamino lleva impreso como único rótulo el de POESIAS / MANUSCRITAS / S. I7; sin embargo, los 106 folios que lo componen pertenecen de puño y letra a don Francisco de Borja y Aragón.

El Príncipe, según parece y aquí se comprueba una vez más, acostumbraba escribir algunos borradores de sus poemas en las cartas que recibía. En el presente caso, unos y otras no desprovistos de interés. Los primeros muestran las diversas fases de su redacción y aun ofrecen varios inéditos; las cartas ayudan a fecharlos aproximadamente. En este trabajo sólo apuntaremos aquellas que interesan por su data, sin ocuparnos del contenido, pues no encontramos ninguna tan importante como la que señaló La Barrera en otro códice del Príncipe ${ }^{1}$. De las trece cartas utilizadas por Esquilache únicamente cinco convienen a nuestro propósito. Enumeramos a continuación los poemas que en ellas aparecen, refiriéndolos a la edición de Amberes de 1663, considerada como definitiva ${ }^{2}$.

En carta de "martes 17 de nobe. 1654 ", fol. $8 \mathrm{r}^{\circ}$, empieza el canto de "El santo y gran Proffeta Hieremias" con que se inician Las nueve lamentaciones... (Obras, págs. 708 y sigs.).

En carta firmada por don Juan de Borja y fechada en Madrid a " 18 de junio de 1636 ", fols. $34 \mathrm{v}^{\circ}$ y $35 \mathrm{r}^{\circ}$, aparecen escritos el estribillo y la copla del romance LIV (ibid., 442), y el romance XCVI, "Memorias del bien que tuuo" (ibid., 468).

1 "El señor don José Cuesta poseía un precioso códice de las poesías de Esquilache, si no autógrafo, escrito bajo la dirección del autor. En él se encuentra colocada una carta autógrafa de Lope al príncipe, declarándole el verdadero sentido de cierto pasaje de una comedia suya" (LA BArrera, Catálogo bibliográfico y biográfico del teatro antiguo español, desde sus orígenes hasta mediados del siglo xviii, Madrid, 1860, pág. 147b).

2 LAS OBRAS / EN VERSO / DE / DON FRANCISCO / DE BORJA, / Principe de Esquilache, Gentil-/hombre de la Camara de Su / Magestad; / DEDICADAS / AL REY / NVESTRO SEÑOR / DON PHILIPE IV. / Edicion postrera, reuista / y muy añadida. / A AMBERES, / EN LA EMPRENTA PLANTINIANA / DE BALTHASAR MORETO. / M. DC. LXIII. 
En carta del Conde de Luna y Ficallo, sobrino del Príncipe, de "Zaragoza y junio 7 de $1650^{\circ}$ ", fols. $5^{1} \mathrm{v}^{0}$ y $5^{2} \mathrm{r}^{\circ}$, la redondilla IV, "Ya no es tiempo de cantar" (ibid., 368) y el romance XX, "Qué pretendéis Cauallero" (ibid., 419).

En carta que firma un "Don Francisco", de "julio $21 / 637$ ", fol. $71 \mathrm{r}^{\circ}$, el romance CLXXVI, "Aquella auecilla triste" (ibid., 513), y, a juzgar por el sello de aguas, también el romance LV, "Que presto sales florido", fol. $70 \mathrm{r}^{\circ}-\mathrm{v}^{\circ}$ (ibid., 443).

En carta firmada por José Ålvaro Queipo de Llano y Valdés, de "Gda. a junio 21 de $1650^{\circ}$ ", fols. $79 \mathrm{v}^{\circ}$ y $80 \mathrm{v}^{\circ}$ (por error de encuadernación), el romance XI, "Entre estas paredes tristes", fol. $79 \mathrm{r}^{\circ}$ (ibid., 413); el soneto XLVI, "No enbidio yo de Príncipes tiranos" (ibid., 24) y el romance XXV, "Si no quieres que te engañe", fol. $80 \mathrm{r}^{\circ}$ (ibid., 430); y la redondilla III, "Lisis, que mal te aconsejan", fol. $80 \mathrm{r}^{\circ}-\mathrm{v}^{\circ}$ (ibid., 367 ).

Publicamos a continuación las catorce piezas del manuscrito autógrafo que no se encuentran en ninguna de las ediciones de Las obras en verso, incluso la "postrera, revista y muy añadida", antes citada. Nuestras anotaciones se limitan a relacionar lo inédito con la vida y obra de Esquilache.

1

Dafne tras vn cieruo con aljaua y arco

De que tu ligereza te aprouecha $o$ cieruo si en [el] lado lleuas rojas con tu sangre las plumas de mi flecha

En vano al agua mísero te arrojas pues soy hija querida de este Río donde aliuiar pretendes tus congojas

$O$ querido Peneo padre mio detenga el fugitiuo tu corriente y demele despues tu arena frio

Porque con su ganchosa altiua frente pueda adornar las aras de Diana cumpliendo el sacro Voto juntamente

No mi oracion en todo a sido vana pues los Arboles mueues y por verme alyas la frente venerable y cana

$\mathrm{Pe}[\mathrm{neo}]-\mathrm{Si}$ assi quisiesses hija complaçerme como yo me accomodo con tu gusto podrias inmortal de nueuo hacerme 
Mira querida dafne que no es justo que niegues a tus años compañia siguiendo vn exerçiçio tan robusto

Sin recelar tu rustica porfia en el rigor de Inuiernos y Veranos ni el Sol ardiente ni la escarcha fria

Fatiguen las montañas y los llanos Villanas plantas, perros y saetas indignas de el cristal de aquessas manos

Quando las cueuas buscas mas secretas en quien de Adonis viue el homicida y no el peligro, ni el furor respetas

[col. 2] Quando para deffensa de la Vida liuyendo la inclemençia de el Imbierno a buscar sale apenas la Comida en vez de hallar esposo dulçe y tierno que a tus floridos años corresponde y en lecho coniugal amor eterno

La fiera buscas en la parte donde en el caliente seno de la cueua de el tiempo y de tus maquinas se esconde

Quien por los montes asperos te lleua? diras que de Diana el exerçiçio tu essenta vida y solitaria aprueua

Mas la virtud tomada por officio quando con el sujeto no conuiene en breue tiempo se conuierte en viçio

$\mathrm{El}$ arco dexa y a tu edad preuiene igual consorte, que en el siglo nuestro gloriosa juventud la selua tiene

Buscarle puedes en la Caca [sic] diestro y con el fuerte amparo de tu esposo no tema tu beldad caso siniestro

Con el persigue al jauali y al osso $Y$ a la noche entre prendas que os recaten succeda al duro afan blando reposo

No esperes que tus años se dilaten y con ellos de el tiempo los agrauios tan gran beldad offendan y maltraten

De un viejo toma los consejos sabios y en paz te queda. 
la cabeça escondio cerro los labios

$\mathrm{Y}$ aunque es su enojo y su impaçiençia mucha yo e de seguir lo que a diana quadre y quiero mas oir entre esta lucha que el arco gima, y el sabueso ladre.

(Fol. $2 \mathrm{v}^{0}$, cols. 1-2).

Este poema se continúa temáticamente en la VII de las Décimas, Consejo de Diana a Daphne, contra el que le dió, para que se casasse, el Rio Peneo su padre (Obras, 36o-361), que también figura en el códice, fol. $2 \mathrm{r}^{\circ}$, con distinto epígrafe: Sale Diana como cacadora [sic] / y Ninfas acompañandola, y la indicación marginal de "Dia[na]". Todo esto, y la forma dialogada del poema que publicamos, nos lleva a pensar que se trata de escenas de alguna frustrada comedia del Príncipe. Existen noticias seguras de que Esquilache no desdeñó este género ${ }^{3}$.

\section{Cançion}

El breue sol de Otubre

entre nubes doradas con desiguales sombras se ponia y de silençio cubre las peñas erizadas la negra noche temerosa y fria reposa el muerto dia quando canto vn ausente el bien que espera y cl dolor que siente

Oras de mi destierro con que la vida engaño en esta injusta soledad amarga. cautiuo soy que el ierro con quexas acompaño hasta que mida amor mi ausençia larga al tiempo se la encarga porque enseñe a mis años memorias tristes, y perdidos años.

$\left(\right.$ Fol. $\left.5 \mathrm{v}^{0}\right)$.

$s$ "También fué obra suya una comedia de capa y espada que se representó en las fiestas que dió en Palacio para la jura del príncipe don Baltasar Carlos la condesa-duquesa de Olivares, Aya que era de Su Alteza Real, según refiere don Antonio Hurtado de Mendoza en la relación de aquel acto, aunque sin expresar su título" (Fernández de Bethencourt, Historia genealógica y heráldica de la monarquía española, Madrid, 1902, vol. IV, pág. 207). 
Sirenas de Mancanares [sic] bien vengais a Nuestra aldea a cantar desafiando las aues de sus riberas las que lleuastes al turia aquellas canciones nueuas que tan suspensas oieron sus flores y sus arenas No calleis callen los aires y escuche la propria tierra las mismas vozes que fueron admiracion de la ajena

No temais mas valiente competencia que la misma que os hazeis quando mas luzis sin ella:

(Fol. $6 \mathrm{r}^{\mathrm{o}}$ ).

\section{4}

Desde que nasce el sol hasta que muere fatiga el campo el labrador cansado y con el hierro coruo del arado de el suelo inculto las espaldas hiere

Los surcos forma y entre los senos quiere dexar el seco grano encomendado a la inclemençia del imbierno elado y della el logro en la cosecha espere

Tambien sembre con desdichada mano burlando mis cansancios y sudores terreno infiel y temporal tirano

No mas sembrar fiado en los rigores de tiempos que al tardio y al temprano los que hazen menos mal, son los mejores.

$\left(\right.$ Fol. $\left.11 \mathrm{r}^{\circ}\right)$.

Compárese la semejanza de este soneto con el XV del mismo Esquilache, "Al fuego ardiente, y en humilde lecho" (Obras, 8) y el LI de Lupercio Leonardo de Argensola, "Vuelve del campo el labrador cansado" ${ }^{4}$.

4 $B A A E E$, vol. XLVII, pág. 277. 
5

Hija en palaçio y Reyna con entrada Vos gustareis lo que escuso la boca y no os valdra ser conde de una roca en tener dura y en gastar cerrada

Si vistes de la Reyna la jornada como tuuistes atençion tan poca sin ver que el golpe que en la bolsa os toca os podia dexar roca tajada?

Animo conde mio aunque se siente el gasto, quien hazerle determina no sera liberal, sera prudente

Despedid la congoxa y la mohina pues no podeis negar que diestramente os encaxo la saya Catalina.

(Fol. $\left.42 v^{0}\right)$.

La alusión del tercer verso no deja lugar a dudas que todo el soneto está dirigido al conde de la Roca, don Juan Antonio de Vera Zúñiga y Figueroa (ca. $15^{80-1658)}$, personaje notable de la corte y escritor citado por Cervantes en el cap. II del Viaje del Parnaso. De su amistad con el Príncipe son prueba el soneto CXLIX, "Del conde de la Roca al Príncipe" (Obras, 75) y la "Respuesta del príncipe por los consonantes" al mismo de la Roca (ibid., 76). También una carta dirigida al Príncipe y que se encuentra sin fecha ni firma en el códice que revisamos, fol. $93 \mathrm{v}^{0}$ :

Lo que se suplica a VE. es q / se sirua de pedir a boca y por / escrito quanto antes a los / señores Conde de la Roca / Marques de Aguila fuen/te y Don Diego sarmien/to que fauorezcan en la / Junta quando se propongan / los oficiales para la Veedu/ría General que se ha for/mado aora. a Don Diego de / Porres secretario que a / sido del Marques de / Mortara que sera hacer / vna muy buena obra el / acomodarle por tener su ma/dre viuda a quien acudir.

\section{6}

Casta y diuina diosa

en quien descansa el trabajado dia

deten la luz hermosa

con que al silencio de la sombra fria

la madeja de plata

en las corrientes aguas se retrata 
Assi de lumbre pura tu blanca frente coronada veas. y logres la hermosura del eterno camino que rodeas con nueuos orizontes en las alegres cumbres de los montes dexa que el sol dorado con nueuo curso presuroso venga a verme lastimado que no seran por mas que se detenga en mis dichas amargas las quexas breues, y las oras largas.

$\left(\right.$ Fol. $\left.63 \mathrm{r}^{\mathrm{o}}\right)$

\section{7}

De la sagrada purpura que vistes y de Aragon celebra la corona mas de su ilustre Rosicler blasona que el Alua de vençer las sombras tristes

Si a la deffensa y al seruicio asistes de el gran Monarca que tu nombre abona haras que en quanto rodeo Latona coraçones no seluas le conquistes

Ya te aguarda en sus montes el Romano por ver tambien de el gran Blason que firmas aunque fue natural, si es honor vano

Ques de Aragon tu gran valor afirmas y que eres Aragon dize tu mano y entrambas cosas firmas y confirmas.

(Fol. $74 \mathrm{r}^{\circ}$ ).

Pocos son los datos que el soneto ofrece para lograr la identificación del personaje a quien va dirigido. Nos inclinamos a creer que se trata de don Gaspar Borja y Velasco (1582-1645), arzobispo de Milán, Sevilla y Toledo, sucesivamente. Como cardenal fué representante de España en la Santa Sede en dos ocasiones. Entre otros importantes cargos que desempeñó, destacamos uno, el de presidente del Consejo Real y Supremo de Aragón, al que bien puede referirse el último terceto. Las relaciones del Príncipe con el cardenal Borja y su posible loanza en este soneto parecen confirmarse en una carta de don Juan de Borja, sobrino del Príncipe, fechada en "Md y Junio .18 . de 1636 ", fols. $34 \mathrm{v}^{\circ}$ y $35 \mathrm{r}^{\circ}$ del códice aquí utilizado; más si se tiene en cuenta que por estos años el de Borja era el primado de los cuatro cardenales españoles: 
Las nueuas de corte. y particularm ${ }^{\text {te }}$. las que / tocan al S. cardenal claro esta que su $\mathrm{em}^{\mathrm{a}}$. / dara quenta dellas a $\mathrm{Vx}^{\mathrm{a}}$. conque me escuso / yo de referirlas solo digo que es $\mathrm{g}^{1}$. la compla / cençia conque çelebran las $\mathrm{m}^{\mathrm{des}}$. conque su magd. / a querido mostrar el agradeçim $^{\text {to }}$. que deue / a sus muchos meritos ...

8

O siempre tenebroso Polifemo

ni es mucho pues si vn ojo tienes solo

donde jamas llego la luz de Apolo

que nunca llega al circular estremo

Contra el Idioma natural, blasfemo

no miraras de lasso el protocolo

pues deste nueuo en la ambicion y dolo

sus versos mas, que su fiereza temo

Qualquier moçuelo que tu Musa inuoque

queda sin que de serlo se auerguençe

poeta culto, de su patria mengua

Bueluete a tu debota insignia aloque y no quieras con rimas en Vascuençe dexar a malas noches nuestra lengua.

(Fol. $75 \mathrm{v}^{0}$, col. 1).

Este soneto puede añadirse a los muchos dirigidos contra Góngora por la escuela tradicional y castellana de los Argensola, especialmente al GLXXIV del propio Príncipe, "Yaze aquí vn Andaluz, Poeta tosco" (Obras, 88).

9

\section{Epi[gramma] Marci[alis]}

Inuitas ad Aprum das mihi gallice porcum ibrida sum si das gallice verba mihi

Conuidasme a jauali

y me das puerco casero

yo janizaro nasçi

$\mathrm{y}$ assi galico en mi fuero

no es engaño para mi.

otra

Conuidasme a jauali

y aunque en puerco le as trocado 
no estoy galico engañado pues janizaro nasçi.

[otra]

Puerco en vez de jauali galico me diste oy y pues janizaro soy no es engaño para mi.

(Fol. $85 \mathrm{r}^{0}$, cols. 1-2).

Una cuarta versión de este epigrama de Marcial (VIII, XxII) aparece en el ms., fol. $85 \mathrm{r}^{\circ}$, col. 2, y es la única publicada, con la sola variante de "genizaro" por "janizaro" (Obras, 404). Al estudio de la influencia de Marcial sobre el Príncipe (traductor además de los epigramas I, XIX, y XIV, LXXv), iniciado por Anthony A. Giulian en su tesis doctoral ${ }^{5}$, conviene añadir estos ensayos de traducción y la animosidad epigramática de los sonetos 5,8 y 11 aquí publicados.

10

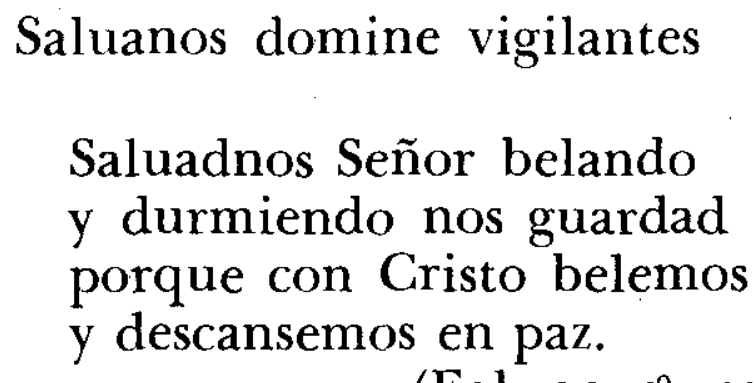

(Fol. $90 \mathrm{v}^{\circ}$, col 1 ).

Esta oración se encuentra en el ms. debajo de otra ya publicada que comienza: "Actiones nostras ...; Señor, nuestras acciones ..." (Obras, 706-707).

\section{1}

Comentador de aquel Luçio Romano por que de mi paciençia tanto abusas si primero inuento cantar las musas don Sebastian Francisco de medrano?

$\mathrm{Y}$ estando impresso en verso castellano no tiene el robo manifiesto escusas y mas saliendo a luz la que rehusas año de treinta y uno, y en Milano

${ }^{5}$ Martial and the epigram in Spain in the sixteenth and seventeenth centuries, Philadelphia, 1930 (University of Pennsylvania Publications of the Series in Romanic Languages and Literatures, XXII), págs. 75-78. 
Que te hizo la Señora de Cetina que dexas sepultado su marido al pie de una inscripcion grecolatina

$\mathrm{Y}$ con dos pedantismos atreuido contra lo que el diffunto determina das al papel, lo que dexo al olvido.

(Fol. $101 \mathrm{r}^{\circ}$ ).

Por los datos que trae deducimos que el soneto va enderezado contra José Antonio González de Salas, traductor de Las Troyanas de Séneca y editor de Quevedo (vs. 1 y 13-14). La obra de Medrano a que se alude, vs. $3-8$, es la recopilación hecha por Castillo Solórzano: Favores de las musas / hechos a don Sebastián / Francisco de Medrano. / En varias Rimas, y Comedias que compuso en la mas / celebre Academia de Madrid donde fue / Presidente meritisimo. / Recopilado por Don Alonso de Castillo / Solorzano intimo amigo del Auctor. / En Milan, por Iuan Baptista Malatesta Impressor / Regio, y Ducal, acosta de Carlo Ferranti librero. / Año 1631. En los Favores de las musas se dividió por primera vez la obra de un escritor en géneros correspondientes a cada una de las musas. La imitación de esta manera ("robo manifiesto") por González de Salas al editar las poesías de Quevedo es evidente: El / PARNASO ESPANOL / Monte en dos cumbres dividido / con las / NUEVE MUSAS CASTELlANAS / Donde se contienen / POESIAS / de Don Francisco de Quevedo Villegas / Caballero de la Orden de Santiago / i señor de la Villa de la Torre de IVAN ABAD: / Que con adorno, i Censura, ilustradas, i corregidas, / salen ahora de la Librería de / Don Ioseph Antonio González de Salas / ... EN MADRID, / ... Año MDCXLVIII. Y explica el oficio de cada musa como en la edición de Medrano. La obra de éste sería sobradamente conocida por el Príncipe, que utilizó una copla suya en la buelta XIV (Obras, 393). A su vez, la estimación de Medrano por Esquilache se deja ver en los Favores, donde lo cita al lado de Lope, Guillén de Castro, Vélez de Guevara, Tirso de Molina: "Quando atendí a un Príncipe de Esquilache, que no se contentó el cielo con hazerle tan illustre en sangre, sino que le igualó con ella el ingenio, tan insigne en todas ciencias, y facultades".

La "señora de Cetina" del v. 9 es la mujer de Quevedo, doña Esperanza de Mendoza, Señora de Cetina, que casó con Quevedo en segundas nupcias el 26 de febrero de $1634^{6}$.

Los vs. 13-14 nos hablan de una pretendida oposición de Quevedo a la publicación - póstuma de sus poesías. Por lo rotundo de la

e Cf. Acta matrimonial en Quevedo, Obras completas. Verso, ed. Astrana Marín, Madrid, 1934, pág. 884. 
afirmación, parece que Esquilache conocía de buena fuente un propósito muy personal de Quevedo, que éste no llegó a expresar en ninguno de sus testamentos ${ }^{7}$.

Esquilache, por otra parte, fué de los primeros en darse cuenta de que la arbitraria manera de Salas al corregir y publicar a Quevedo era por demás perjudicial, como que ha invalidado muchos trabajos de la moderna crítica. Quizá a él se refiera cuando explica por qué reúne e imprime sus propios versos; en la primera página dice "El Príncipe a su Libro":

Y así claro seré yo:

Sabrán todos lo que dixe,

Mas no lo que el otro elige,

Que por sí me comentó.

Aparentemente las relaciones entre ambos fueron cordiales. Salas dedicaba la Cuarta Musa "al mui excelente señor don Francisco de Borja" (Parnaso, 255), y en la explicación de la misma lo colmaba de elogios (ibid., 262). El Príncipe, por su parte, dirigía "A Don Iusepe Antonio de Salas, auiendo visto su libro de la Tragedia", la décima XXIII (Obras, 401): "Señor, el libro leí / Con respeto y con amor..." Quizá a esto se deba que Esquilache dejara inédito el presente soneto.

Psal 9

Confitebor tibi domine

Yo Señor os confiesso con todo el coraçon constante y llano y celebrar professo las obras grandes de essa eterna mano y con Vuestra alegria cantar el nombre altissimo queria.

(Fol. $102 \mathrm{r}^{\circ}$ ).

El Príncipe, traductor de los Psalmos de David, sólo alcanzó a publicar (traducidos al lado de la versión latina y su Argumento) los Psalmos I-VIII, XLI, L y CXXXVI (Obras, 664-707).

Si bien le quisiste

si engañada estaua

- Ibid., pág. 889. Conviene apuntar que si allí nada se dispone expresamente respecto de las obras de Quevedo ni se alude a González de Salas, en cambio aparece nombrado entre los albaceas el Duque de Medinaceli, patrocinador tres años más tarde de la edición del Parnaso. 


$$
\begin{aligned}
& \text { no quieras tu gusto } \\
& \text { tus venganças ama } \\
& \text { Procuralas niña } \\
& \text { que en mujer burlada } \\
& \text { fue el mayor de todos } \\
& \text { siempre la vengança } \\
& \text { Pues vio etc. }
\end{aligned}
$$

$$
\text { (Fol. } 104 \mathrm{r}^{\circ}, \text { col. } 1 \text { ). }
$$

\section{4}

Que dicha me asseguro

si de verte Señora

offendo la esperança con la muerte

que engaño mal seguro

el sufrimiento llora.

Si amor procura que a vençer açierte

calle su dura suerte

que aunque la pena es graue

sufrirla puede quien cantarla sabe.

(Fol. $106 \mathrm{r}^{\circ}$ ).

Una vez más, "lo que el difunto determina" dejar para el olvido futuro sirve, si no para elevar su obra, al menos para matizarla y ambientarla. No ha sido otro nuestro propósito al dar estas poesías al papel.

Ernesto Mejía Sánchez

Luis Alberto Ratto

Santander, agosto de 1953. 